\title{
Increased serum levels of Galectin-9 in patients with chronic lymphocytic leukemia
}

\author{
KAMIL WDOWIAK $^{1}$, ENRIQUE GALLEGO-COLON ${ }^{2}$, TOMASZ FRANCUZ ${ }^{1,2}$, \\ PAULINA CZAJKA-FRANCUZ ${ }^{1}$, NATALIA RUIZ-AGAMEZ ${ }^{2}$, MARCIN KUBECZKO ${ }^{3}$, \\ IGA GROCHOŁA $^{1}$, MACIEJ T. WYBRANIEC ${ }^{4}$, JERZY CHUDEK ${ }^{1}$ and JERZY WOJNAR ${ }^{1}$
}

\author{
${ }^{1}$ Department of Internal Medicine and Oncological Chemotherapy, Silesian Medical University, Katowice 40-027; \\ ${ }^{2}$ Department of Biochemistry, Silesian Medical University, Katowice 40-752; \\ ${ }^{3}$ Clinical and Experimental Oncology Department, Maria Skłodowska-Curie Memorial Cancer Center and Institute of Oncology, \\ Gliwice Branch, Gliwice 44-101; ${ }^{4}$ First Department of Cardiology, School of Medicine in Katowice, \\ Medical University of Silesia, Katowice 40-635, Poland
}

Received March 13, 2018; Accepted September 11, 2018

DOI: $10.3892 / \mathrm{ol} .2018 .9656$

\begin{abstract}
Chronic lymphocytic leukemia (CLL) is the most common type of leukemia in adults. Despite improvements in treatment, CLL is still considered an incurable disease. The aim of the present study was to evaluate galectin-1, -3 and -9 (Gal-1, -3 and -9 ) and Gal-3 binding protein (Gal-3BP) as prognostic and predictive factors in patients with CLL. Serum concentrations of Gal-1, -3 and -9 and Gal-3BP were measured in 48 patients with CLL and 30 control patients, using multiplex bead arrays. In patients with CLL, galectin concentrations were assessed prior to, during and following treatment. In patients with CLL who were untreated, galectin concentrations were measured twice with a 6-month interval. The serum level of Gal-9 was significantly increased $(\mathrm{P}<0.0001)$ in patients with CLL compared with the control group, and was associated with the clinical stage according to Binet classification, as well as poor cytogenetic and serum CLL prognostic factors. In addition, patients with CLL, who exhibited treatment failure, exhibited higher concentrations of Gal-9 $(\mathrm{P}=0.06)$ and Gal-3BP $(\mathrm{P}=0.009)$ at the end of the treatment when compared with patients under complete remission or stabilization of the disease. The serum level of Gal-3 was significantly decreased $(\mathrm{P}=0.012)$ in patients with CLL compared with the control group. These results suggest that Gal-9 is a potential prognostic factor in patients with CLL. The predictive value of Gal-9 requires further study in larger cohorts of patients.
\end{abstract}

Correspondence to: $\mathrm{Dr}$ Tomasz Francuz, Department of Biochemistry, Silesian Medical University, ul. Medyków 18, Katowice 40-752, Poland

E-mail: tfrancuz@sum.edu.pl

Key words: galectins, chronic lymphocytic leukemia, prognostic factor

\section{Introduction}

Chronic lymphocytic leukemia (CLL) is the most common type of adult leukemia in Western countries with a large percentage of asymptomatic patients, and may be detected only incidentally during routine examinations $(1,2)$. CLL is a disease that exhibits a gradual onset, and is characterized by the accumulation of small defective $\mathrm{CD}^{+} \mathrm{B}$ lymphocytes in the blood, bone marrow and lymphoid organs (3). The disease presents with subtle and heterogeneous symptoms, including fever, night sweats, weight loss, lymphadenopathy, anemia, and thrombocytopenia that are often missed at early stages (1). Even following diagnosis, due to the slow progression of CLL, patients may not require chemotherapeutic treatment $(2,3)$.

The heterogeneous presentation and clinical course of CLL makes stratification of patients into appropriate risk and treatment groups of great importance. CLL has been associated with chromosomal abnormalities, including trisomy 12q (16\%), deletion of $11 \mathrm{q}(18 \%)$ and deletion of $17 \mathrm{p}[7 \%$, containing tumor protein p53 (TP53)], which is associated with a shorter survival time, aggressiveness of disease and extensive lymph node involvement $(4,5)$. Notably, the most common chromosomal aberration, deletion of 13q (55\%), correlates with good prognosis in $55 \%$ of patients with CLL $(4,5)$. CLL heterogeneity is partially caused by microRNA $(6,7)$, epigenetic (8) and microenvironment alterations (3). At present, the strongest prognostic indicator in CLL is the mutational status of the immunoglobulin heavy-chain variable region (IGHV), which predicts clinical prognosis at diagnosis $(9,10)$. Mutation of IGHV is correlated with slower disease progression and an increased survival time, in addition to the less advanced Binet stage A disease (11). However, routine determination of this biomarker is not a cost-effective measure, and thus not widely used. Other markers, including CD38 and ZAP70, have also been investigated as surrogates for IGHV status $(12,13)$; however, a reliable marker has yet to be identified. CD38 expression correlates with non-mutated IGHV, adverse disease course and severity, whereas ZAP70 expression is associated with mutated IGHV 
and an improved disease outcome (12-18). For $>40$ years, Rai and Binet staging systems have served as standardized systems to categorize patients, provide patient care and administer adequate cancer therapy $(19,20)$. However, in order to continue to improve patient outcomes, more accurate prognostic markers are required. Additionally, important factors, such as lactate dehydrogenase (LDH) and $\beta 2$ microglobulin (B2M) indicate the proliferation and activity of the disease (21). Lower B2M serum concentrations have been identified as beneficial prognostic factors associated with a higher response rate, longer disease-free time and overall survival (OS) times (21). However, in clinical practice, the prognostic and predictive value of $\mathrm{B} 2 \mathrm{M}$ and LDH remains insufficient. Therefore, it is imperative to identify novel indicators that may aid clinicians in making an informed decision regarding when to begin treatment.

The 'sugarcode', or protein glycosylation pattern, serves a role in intra- and intercellular communication, and exhibits functions in regulatory processes, including those dysregulated in cancer and metastasis (22-24). Galectins are glycan-binding proteins of the lectin family, and are central effectors of this form of communication, and their role has previously been implicated in the development of cancer (25). All 15 of the galectins identified in humans share a highly conserved carbohydrate recognition domain (CRD) that recognizes and binds $\beta$-galactosides (26). This CRD-mediated pattern recognition mechanism promotes galectin binding to specific cell surface receptors, activating intracellular signaling pathways involved in immune response, cell adhesion, communication, proliferation, differentiation and migration $(27,28)$. The role of galectins in cancer progression is an area of interest in current research. Different galectins are associated with tumor progression and suppressive mechanisms that are specific to the type of tumor (29). High plasma levels of galectins $-2,-4,-8$ and -10 (Gal-2, $-4,-8$ and -10$)$ have been observed in patients with various types of malignancy, including ovarian carcinoma, prostate cancer and metastatic diseases $(30,31)$. Galectins induce the secretion of cytokines and chemokines, including granulocyte colony-stimulating factor, interleukin- 6 and chemokine $(\mathrm{C}-\mathrm{X}-\mathrm{C})$ motif ligand 1 , thereby promoting cancer-endothelial cell adhesion and promoting metastasis $(30,32)$. Gal-9 also serves a central role in tumor cell-induced T-cell exhaustion in CLL (32). Taglihoo et al (32) identified that Gal-9 levels were increased 30-fold in the malignant cells of patients with CLL. Levels of PL-1, a known effector of apoptosis in T cells, were also increased. Additionally, extracellular Gal-3 has been demonstrated to induce T-cell apoptosis in melanoma, and its suppression leads to enhanced migration and invasion of choloangiocarcinoma cells (33). Reduced levels of Gal-3 enhance the activation of apoptosis via cell-to-cell contact (33). Notably, low Gal-3 levels are associated with a progressive form of cervical neoplasia (34). In addition, intracellular Gal-3 may be involved in mRNA splicing and correlates with poor prognosis (35-37). Gal-9 is able to bind Tim-3, preventing T-cell activation and triggering cell death in Tim- $3^{+}$ $\mathrm{T}$ cells (38-40). This dampening of the T-cell mediated immune response is also supported by Gal-1 expression, which induces anti-inflammatory macrophage activation and expansion of the regulatory T-cell compartment $(26,41,42)$. Due to the role of galectins in cancer progression, the aim of the current study was to evaluate serum levels of galectins as potential prognostic factors in patients with CLL.

\section{Materials and methods}

Patients. This prospective study included 52 patients (Tables I and II) with CLL admitted to the Department of Internal Diseases and Oncological Chemotherapy (Mielęcki's Independent Public Clinical Hospital of the Silesian Medical University in Katowice) for immunochemotherapy or chemotherapy between March 2013 and September 2017, and 30 non-CLL patients as control subjects. Control patients were admitted to the Department of Endocrinology (Mielęcki's Independent Public Clinical Hospital of the Silesian Medical University in Katowice) for routine MRI imaging of adrenal gland incidentaloma. None of the control patients had a hormonally active tumor or CLL. Patients with CLL were classified according to the Binet staging system $(19,20)$. The exclusion criteria were as follows: Other malignancies, acute inflammatory diseases or a history of renal or liver disease or heart failure (>New York Heart Association Functional Classification III/IV). Based on the exclusion criteria, 4 patients with CLL were disqualified from the study. Therefore, a total of 48 patients, 23 male and 25 female patients, with an average of 64 years of age, with CLL were included. Additionally, all patients in the control group met the exclusion criteria. Study subjects underwent assessment of total blood count, serum activity of LDH, and levels of B2M, creatinine, glucose and immunoglobulins $\operatorname{IgG}, \operatorname{IgA}$ and IgM. A bone marrow biopsy was performed in each patient. Additionally, fluorescent in situ hybridization was performed to assess chromosomal abnormalities, including del11q, del17p and del13q, as well as trisomy of chromosome 12 . The decision between initiation of chemotherapy or a 'watchful waiting' strategy was made according to the International Workshop on Chronic Lymphocytic Leukemia (IWCLL) guidelines (43-45). Patients with CLL who required systemic treatment received chemotherapy comprising rituximab, fludarabine, cyclophosphamide, vincristine, prednisone and bendamustine (R-FC, $\mathrm{R}-\mathrm{COP}$ or R-B schemes) according to schedules based on the patient's clinical condition. The present study was performed in adherence with the Declaration of Helsinki Guidelines and was approved by the Bioethics Committee of Silesian Medical University in Katowice (approval no. KNW/0022/KB1/102/13). Upon admission, all patients provided written informed consent for their participation in this project.

Blood samples. Blood (10 ml) was collected from each subject prior to chemotherapy. Whole blood samples were stored in Vacutainer tubes containing a coagulation activator, and were left to clot. Following $20 \mathrm{~min}$ of incubation at room temperature, the samples were centrifuged for $10 \mathrm{~min}$ at $1,000 \mathrm{x} \mathrm{g}$ at room temperature. Serum aliquots were frozen and stored at $-176^{\circ} \mathrm{C}$ in liquid nitrogen until subsequent analysis. In addition, patients with CLL who underwent treatment were re-evaluated during chemotherapy (3 months) and following chemotherapy (6 months). Untreated patients with CLL (with stable disease, $\mathrm{SD})$ were re-evaluated for the second measurement at 6 months. Control patients were assessed during the same period.

Fluorescent bead-based Luminex cytokine assay. Analysis of galectin protein concentrations was performed in patient sera using multiplex, bead-based assays customized for 
Table I. Clinical and laboratory patient information in control and patients with chronic lymphocytic leukaemia.

\begin{tabular}{|c|c|c|c|c|c|}
\hline Variable & Control & Upper-lower quartile & CLL patients & Upper-lower quartile & P-value \\
\hline Age & 64 & $72-55$ & 70.5 & $76-65$ & 0.027 \\
\hline Platelet $\left(10^{9} / 1\right)$ & 238.6 & $270-205$ & 160.81 & $203-111$ & $<0.001$ \\
\hline Haemoglobin (g/l) & 13.93 & $15.3-12.7$ & 12.23 & $14.1-10.9$ & 0.001 \\
\hline Leukocytes $\left(10^{9} / 1\right)$ & 7.61 & $8.86-5.87$ & 68.59 & $89.62-24.44$ & $<0.001$ \\
\hline BMI & 27.52 & $29.72-25.56$ & 27.32 & $29.75-24.35$ & 0.430 \\
\hline \multicolumn{6}{|l|}{ Comorbidities } \\
\hline Anaemia & $1(33.3 \%)$ & & $19(36.5 \%)$ & & $<0.001$ \\
\hline Low platelets & $3(10.0 \%)$ & & $23(44.2 \%)$ & & 0.001 \\
\hline $\mathrm{DM}$ & $6(20.0 \%)$ & & $11(21.2 \%)$ & & 0.569 \\
\hline CHD & $13(43.3 \%)$ & & $21(40.4 \%)$ & & 0.487 \\
\hline
\end{tabular}

Data are presented as median (interquartile range) or mean \pm standard deviation (SD). Paired t-test Fisher. DM, Diabetes mellitus; CHD, chronic heart disease, CLL, chronic lymphocytic leukemia. One-way analysis of variance with Bonferroni post-hoc test.

Table II. Clinical patient information in control and patients with chronic lymphocytic leukaemia.

\begin{tabular}{|c|c|c|c|c|c|c|}
\hline CLL staging & Control & CLL patients & LN involvement & Spleen involvement & LDH (SD) & $\mathrm{B} 2 \mathrm{M}(\mathrm{SD})$ \\
\hline Binet $\mathrm{A}$ & $\mathrm{n} / \mathrm{a}$ & 14 & 10 & 1 & $157.8 \pm 23.99$ & $3,444 \pm 1546$ \\
\hline Binet B & $\mathrm{n} / \mathrm{a}$ & 15 & 14 & 8 & $199.9 \pm 51.53$ & $4,671 \pm 2187$ \\
\hline Binet $\mathrm{C}$ & $\mathrm{n} / \mathrm{a}$ & 19 & 20 & 15 & $231.4 \pm 99.64^{\mathrm{a}}$ & $5,169 \pm 2915$ \\
\hline CLL males & 10 & 23 & & & & \\
\hline CLL females & 20 & 25 & & & & \\
\hline $\mathrm{N}$ & 30 & 48 & & & & \\
\hline
\end{tabular}

Data are presented as median (interquartile range) or mean \pm standard deviation (SD). CLL, chronic lymphocytic leukemia; LDH, lactate dehydrogenase; B2M, $\beta 2$ microglobulin; $\mathrm{LN}$, lymph node. ${ }^{\mathrm{a}} \mathrm{P}<0.05$.

the selected galectins (cat. no., LXSAHM; R\&D Systems, Inc., Minneapolis, MN, USA) according to the manufacturer's protocol. Galectin protein levels were analyzed prior to chemotherapy, during chemotherapy (3 months) and following chemotherapy (6 months). All the detection antibodies used produced a single band in the western blot analysis, with a molecular mass corresponding to the detected galectin (data not shown). Where available, except standards (recombinant human galectins), external galectin standards were used to assess potential cross-reactivity. No significant cross-reactivity or sensitivity issues were identified among the assayed galectins (data not shown). According to the multiple bead-based assay manufacturer's protocol, biotinylated anti-Gal-9 antibody has $<2 \%$ cross-reactivity with rhGalectin-1, rhGalectin-2, rhGalectin-7 and rhGalectin-8. Due to the different dilutions required for the assay, separate assays were performed for Gal-1 and Gal-9, and Gal-3 and Gal-3BP. Data were acquired on a validated and calibrated Bio-Plex 200 system (Bio-Rad Laboratories, Inc., Hercules, CA, USA) and analyzed with Bio-Plex Manager 6.0 software (Bio-Rad Laboratories, Inc.) with a detection target of 50 beads/region, low RP1 target for CAL2 calibration, and recommended doublet discriminator gates of 8,000-16,500 for Bio-Plex. The median fluorescence intensity was measured.
Statistical analysis. Statistical analysis was performed using Statistica (version 10; StatSoft, Inc., Tulsa, OK, USA) and MedCalc v.14.8.1 (MedCalc Software bvba, Ostend, Belgium) software packages. Continuous variables are expressed as the mean \pm standard error of the mean (normally distributed) or as the median and interquartile range (non-normally distributed). The type of distribution was established based on the Shapiro-Wilk test. Qualitative variables were expressed as crude values and percentages. Intergroup differences for normally distributed quantitative variables were assessed using the paired student's t-test or one-way analysis of variance followed by Dunnett's multiple comparison post hoc test. The Kruskal-Wallis test was applied for parameters with a skewed distribution. Temporal variations of different variables were evaluated using the paired student's t-test for dependent samples or Wilcoxon matched pairs test. Mortality or disease progression were defined as dependent variables for the purpose of the univariate and multivariate Cox proportional hazards model, whereas independent variables were designated from among baseline and laboratory parameters, including plasma galectin concentration. Hazard ratios with 95\% confidence intervals were calculated. Kaplan-Meier estimator curves were established and compared using the log-rank test in order to compare survival between qualitative 

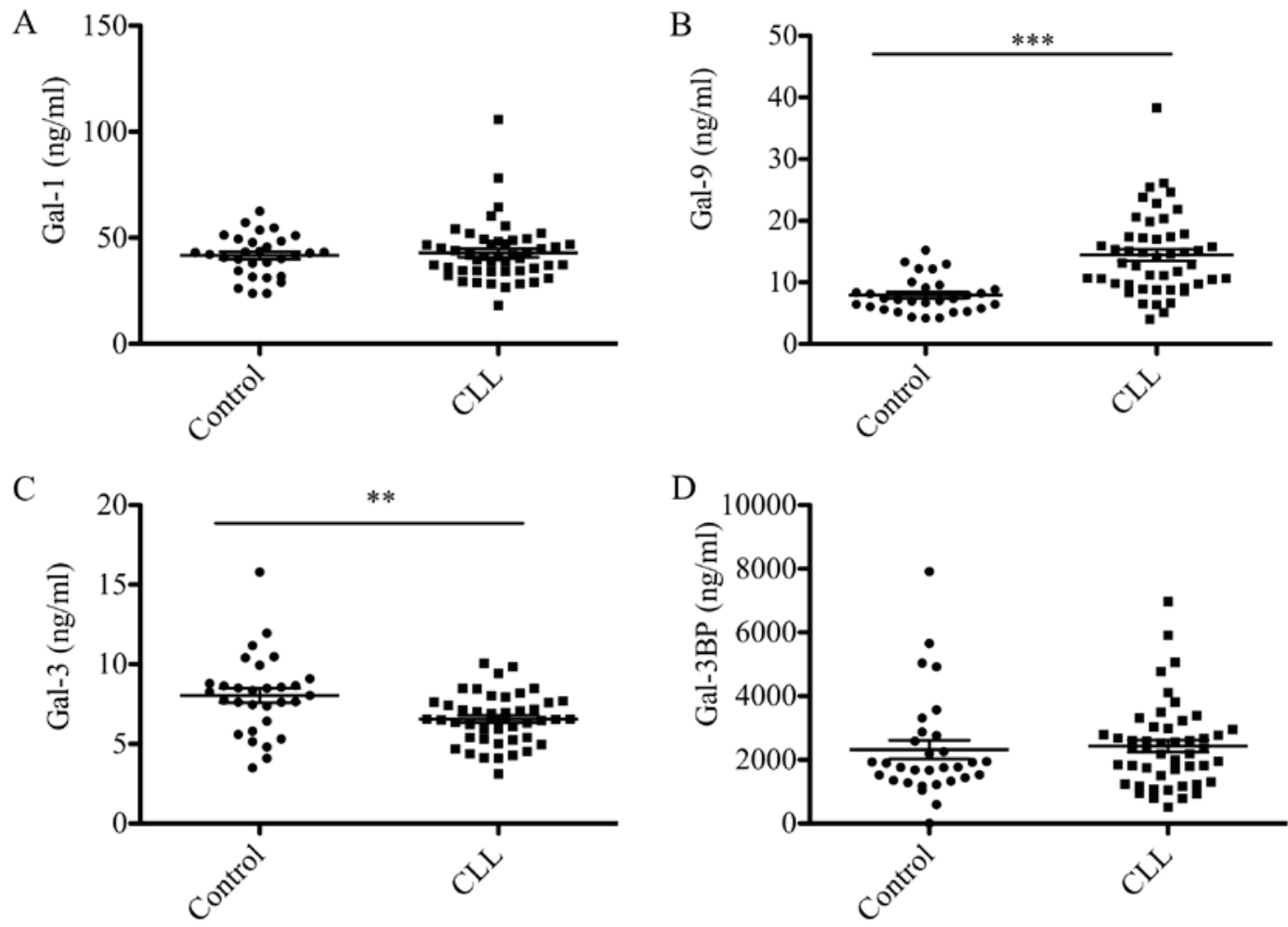

Figure 1. Galectin serum levels in patients with CLL and the control group. Concentration of (A) galectin-1, (B) galectin-9, (C) galectin-3 and (D) galectin 3 -binding protein was measured. Data are presented as the mean \pm standard error of the mean. Control $(n=30)$, CLL ( $n=48)$. Differences between two groups were analyzed using paired student's t-test. ${ }^{* *} \mathrm{P}<0.001,{ }^{* * *} \mathrm{P}<0.0001$. CLL, chronic lymphocytic leukemia.

parameters. $\mathrm{P}<0.05$ was considered to indicate a statistically significant difference. Spearman's Rank-Order correlation was used to perform correlation analysis between GAL-9 and LDH and GAL-9 and B2M.

\section{Results}

Patient characteristics. Patients were stratified according to Binet staging (Tables I and II) and subdivided according to disease progression. Significant differences in age, platelets, hemoglobin and leukocytes were observed between patients with CLL and the control group (Tables I and II). No significant increases in comorbidities were observed in the CLL group when compared with the control group.

Serum concentrations of Gal-1, -3, -9 and Gal-3BP in patients with CLL. Gal-1, -3, -9 and Gal-3BP levels in the sera from 48 patients with CLL and 30 control subjects are presented in Fig. 1. Gal-9 levels were significantly elevated in patients with CLL compared with the control group (14 vs. $8 \mathrm{ng} / \mathrm{ml}$; $\mathrm{P}<0.0001$; Fig. 1B), whereas Gal-3 levels were significantly reduced ( 7 vs. $8 \mathrm{ng} / \mathrm{ml}$; $\mathrm{P}<0.05$; Fig. $1 \mathrm{C}$ ). No statistically significant differences in Gal-1 and Gal-3BP protein were observed between patients with CLL and the control group (Fig. 1A and D).

Association between galectin levels and CLL prognostic factors. Association analysis between negative cytogenetic factors, including deletions of 11q (del11q), 17p (del17p) and $13 q$ (del13q), were analyzed (Fig. 2). Patients with del11q and del17p presented with higher levels of Gal-9 when compared with patients with CLL and no chromosomal abnormalities (17 vs. $12 \mathrm{ng} / \mathrm{ml}$; $\mathrm{P}<0.05$; Fig. 2A). When analyzed individually, patients with del11q exhibited a statistically significant increase in levels of Gal-1 (39 vs. $10 \mathrm{ng} / \mathrm{ml}$; $\mathrm{P}<0.001$ ) and Gal-9 (13 vs. 9 ng/ml; $\mathrm{P}<0.05)$ compared with patients with CLL and no chromosomal abnormalities (Fig. 2B and C). Conversely, patients with deletions in del13q presented a significant decrease in Gal-9 levels (13 vs. $18 \mathrm{ng} / \mathrm{ml} ; \mathrm{P}<0.05$ ) when compared with the CLL group with no chromosomal abnormalities (Fig. 2D). No significant differences were observed in galectin levels when patients presented with del17p (data not shown). Furthermore, a significant correlation was observed between Gal-9 serum concentration and CLL prognostic factors, including $\mathrm{LDH}$ activity $(\mathrm{P}<0.0001)$ and B2M level ( $\mathrm{P}<0.0001$; Fig. 3).

Serum concentration of Gal-9 correlates with clinical stage of CLL. Serum concentrations of Gal-1, -9 and -3 and Gal-3BP stratified according to patient stage are presented in Figs. 4 and 5 and Tables I and II. Prior to chemotherapy, patients with CLL at Binet stages B and C exhibited increased levels of Gal-9 (17 and $15 \mathrm{ng} / \mathrm{ml} ; \mathrm{P}<0.001$ and $\mathrm{P}<0.05$, respectively), when compared with patients with CLL at Binet stage A (10 ng/ml; Fig. 4). Following chemotherapy, Gal-9 levels remained elevated in patients with Binet C CLL when compared with patients with Binet A CLL (Fig. 4B). Gal-1, Gal-3 and Gal-3BP levels remained unchanged (Fig. 4A, $\mathrm{C}$ and D). Patients in Binet A stage exhibited a significant reduction in Gal-9 protein concentration compared with 

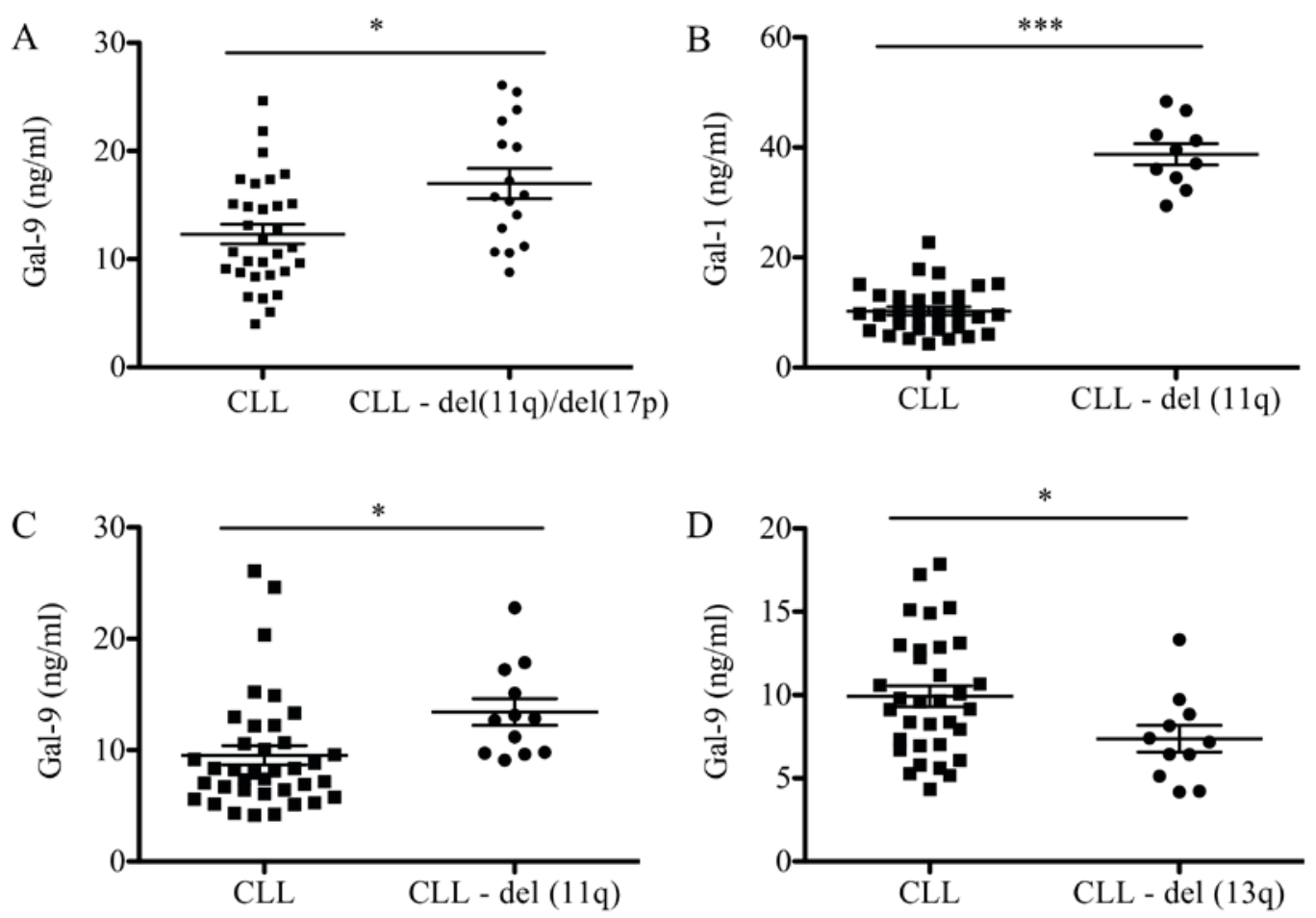

Figure 2. Galectin protein levels in patients with CLL and chromosomal abnormalities. Concentration of (A) Gal-9 in patients with CLL with del(11q) and del (17p). (B) Protein levels of Gal-1 and (C) Gal-9 in patients with CLL with del (11q). (D) Protein levels of Gal-9 in patients with CLL with del(13q) were measured. Data are presented as the mean \pm standard error of the mean. Low-risk and normal-risk CLL ( $\mathrm{n}=32$ ), high-risk CLL ( $\mathrm{n}=16$ ). Differences between two groups were analyzed using paired student's t-test. "P<0.05 and ${ }^{* * *} \mathrm{P}<0.0001$. CLL, chronic lymphocytic leukemia; Gal, galectin.

patients in Binet $\mathrm{C}$ stage at 6 months following chemotherapy (9 vs. $15 \mathrm{ng} / \mathrm{ml}$; P<0.05; Fig. 4B).

Furthermore, galectin protein levels were analyzed prior to chemotherapy, during chemotherapy (3 months) and following chemotherapy (6 months; Fig. 5). The follow-up Gal-1 and Gal-3 levels remained unchanged (Fig. 5A and C). Notably, patients in Binet B stage exhibited a progressive reduction in Gal-9 levels during the follow-up time $(17,14$ and $12 \mathrm{ng} / \mathrm{ml}$, respectively; $\mathrm{P}<0.05$; Fig. 5B). Additionally, Gal-3BP levels increased in patients in Binet $\mathrm{C}$ stage compared with patients in Binet A stage, following chemotherapy (23 vs. $17 \mathrm{ng} / \mathrm{ml}$; $\mathrm{P}<0.05$; Fig. 5D).

Galectins as prognostic markers for response to treatment and survival. Galectin levels in patients with CLL were evaluated according to the type of response to chemotherapy (Fig. 6). The response to chemotherapy was evaluated according to IWCLL criteria (43-45). Patients with SD exhibited a significant reduction in Gal-9 concentration compared with patients who achieved partial response (PR; 9 vs. $18 \mathrm{ng} / \mathrm{ml}$; $\mathrm{P}<0.05)$. No significant associations between Gal-1 or Gal-3BP (Fig. 6A and D) and response to treatment were identified. Notably, untreated patients with SD exhibited lower Gal-9 levels compared with patients who achieved complete remission (CR) following chemotherapy, as well as with patients who exhibited disease progression (PD) and patients who succumbed to the disease during the treatment (Fig. 6B). Notably, Gal-3 levels were significantly elevated in patients who succumbed to the disease compared with patients with $\mathrm{CR}, \mathrm{PR}, \mathrm{SD}$ and $\mathrm{PD}$, with the PD group exhibiting the lowest Gal-3 concentration (Fig. 6C). The established negative prognostic factor for CLL, LDH, did not exhibit a statistically significant difference.

To evaluate the prognostic value of galectin levels in CLL patient sera, Kaplan-Meier survival curves were plotted for Gal-1, Gal-3, Gal-9 and Gal-3BP according to galectin concentration $>75$ th percentile (Fig. 7). During follow-up, 9 patients succumbed and 10 exhibited PD. The median time of progression free survival (PFS) for the CLL group was 19.5 months and an elevated risk of mortality was observed when Gal-9 levels were elevated; however, this was not statistically significant $(\mathrm{P}=0.19$; Fig. 7B). No significant results were observed for elevated Gal-1, Gal-3 and Gal-3BP in the prediction of shorter OS or PFS times (Fig. 7A, C and D). COX analysis indicated no significant results for galectins in the prediction of mortality or progression. A trend was observed in Gal-3 concentration measured prior to treatment $(\mathrm{P}=0.056$; Fig. $7 \mathrm{C})$.

\section{Discussion}

Galectins are members of the lectin family, which exhibit a high affinity for $\beta$-galactosides. The galectin-glycan conjugate serves a fundamental role in metastasis, angiogenesis, tumor immunity, proliferation and apoptosis $(25,26)$. Unfortunately, the mechanism of action and potential therapeutic implications of galectins in cancer are not yet fully understood $(29,32,46)$. In a study by Asgarian-Omran et al (29), low mRNA expression of the Gal-3 gene was observed in the leukemic cells of patients with CLL, and no significant difference was observed in Gal-1 mRNA between CLL patients and control subjects. In addition, expression of Gal-3 mRNA was lower in patients with 

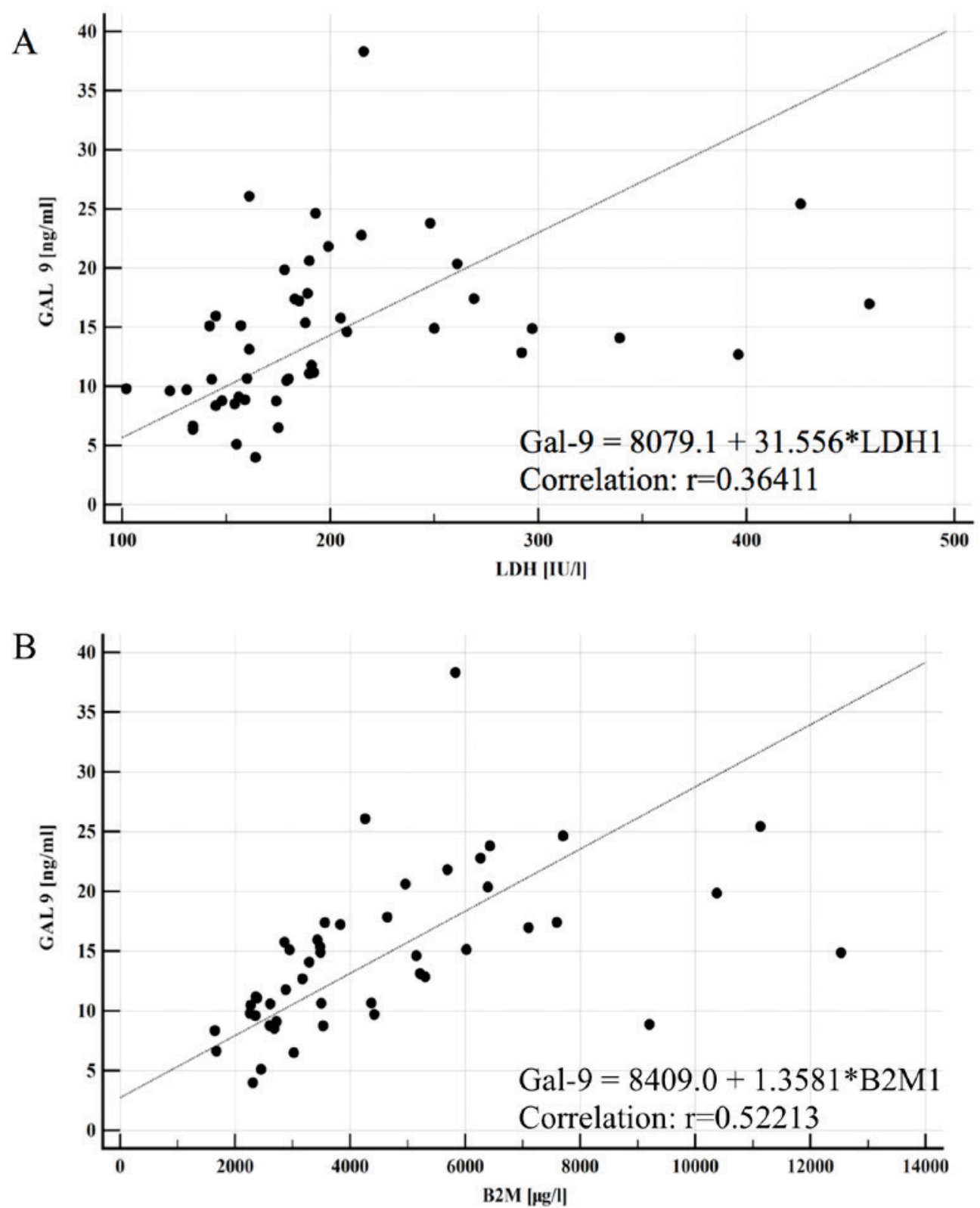

Figure 3. Correlations between Gal-9 and CLL prognostic factors. (A) Gal-9 and LDH activity. (B) Gal-9 and $\beta 2$ microglobulin. Correlations were determined by Spearman's rank order (rs). CLL, chronic lymphocytic leukemia; Gal-9, galectin-9; LDH, lactate dehydrogenase; B2M, $\beta 2$ microglobulin.

progressive disease. In the current study, a reduction in Gal-3 plasma levels was observed in patients with CLL compared with controls. In a study by Taghiloo et al (32), galectin levels were compared in 25 patients with CLL and 15 healthy subjects, and high mRNA expression levels of Gal-9 were observed in mononuclear cells of patients with CLL. In a previous study, plasma levels of Gal-1 were measured in 49 patients with CLL and 40 healthy subjects, the study revealed an increase in Gal-1 in patients with CLL compared with healthy subjects (32). In patients at Binet $\mathrm{C}$ stage, plasma Gal-1 levels were identified to be increased $>2$-fold when compared with patients at stage Binet A (517 vs. $208 \mathrm{ng} / \mathrm{ml}$ ) (46). However, in the current study, Gal-1 levels were similar between CLL and controls. There are limitations to the present study, for example, at the design stage, the association between IGHV, and Gal-1 and Gal-3 levels were not investigated as according to the literature, the mutational status of the IGHV has no effect on the expression of Gal-1 and Gal-3 (29). Additionally, due to the limited number of patients enrolled in the present study, statistical analyses to assess the association between galectin level and mutational status of IGHV were not performed. The beta value of statistical analysis would not be strong enough to support a possible negative result indicating that there is no correlation between galectin levels and mutational status.

To the best of our knowledge, the current study is the first to describe that patients with CLL exhibit higher serum concentrations of Gal-9, which is associated with the stage of disease. Consistent with these results, Kikushige et al (47) observed higher concentrations of Gal-9 in sera of patients and mice with acute myeloid leukemia (AML) compared with healthy subjects. AML cells secrete Gal-9 via an autocrine loop, which leads to activation of T-cell immunoglobulin and mucin domain-containing protein 3 receptor (Tim-3). Gal-9-dependent T-cell activation promotes leukemic stem cell self-renewal (47). 

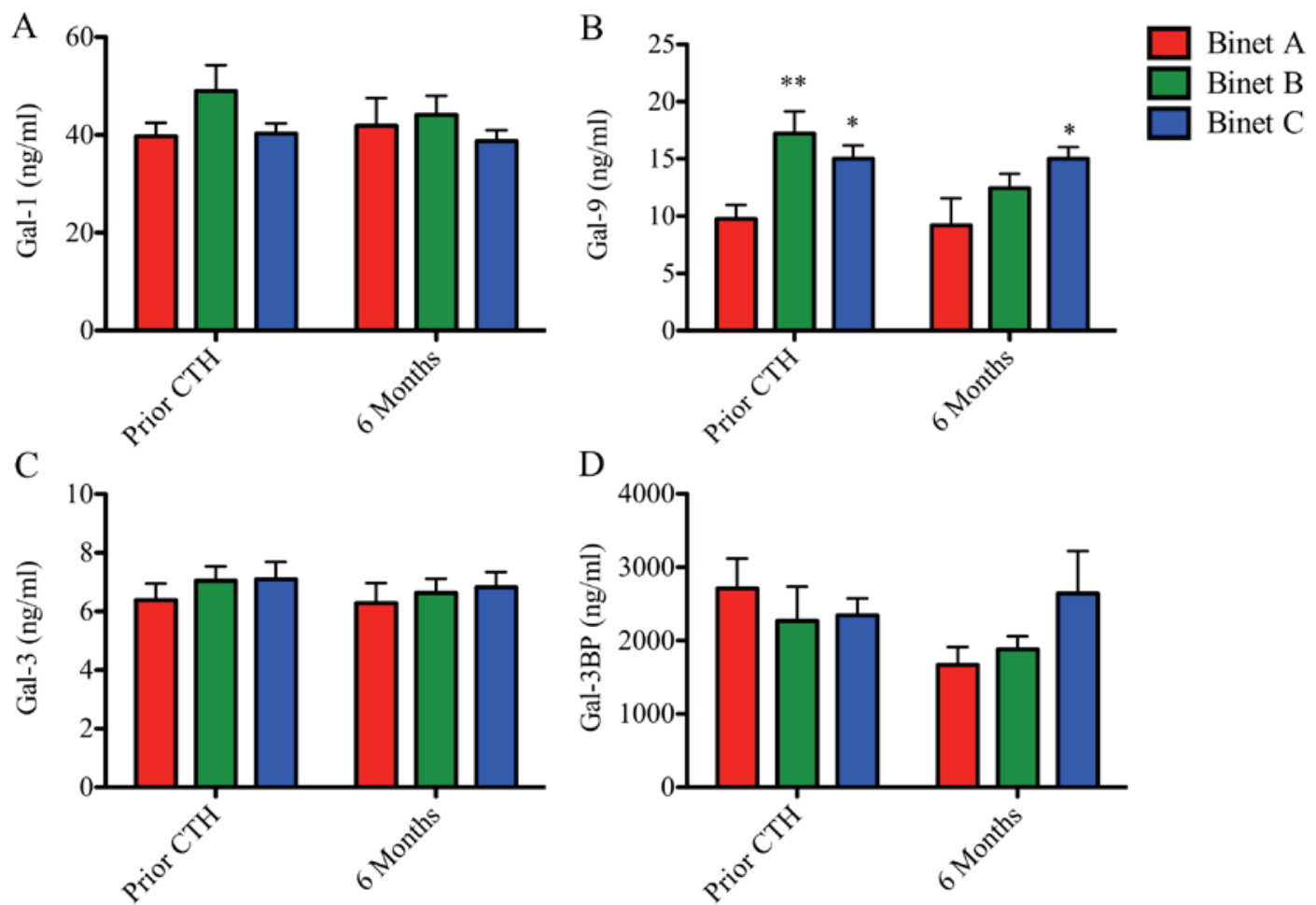

Figure 4. Galectin serum levels and clinical status in patients with CLL prior to and following chemotherapeutic treatment. Concentration of (A) galectin-1, (B) galectin-9, (C) galectin-3 and (D) galectin 3-binding protein in patients with CLL at Binet stage A, B or C. Data are presented as the mean \pm standard error of the mean. Binet A $(n=14)$, Binet B $(n=15)$ and Binet C $(n=19)$. Data were analyzed using one-way analysis of variance followed by Dunnett's multiple comparison post-hoc test. ${ }^{*} \mathrm{P}<0.05$ for Binet $\mathrm{C}$ or ${ }^{* *} \mathrm{P}<0.001$ for Binet $\mathrm{B}$ when compared with Binet $\mathrm{A}$, respectively, prior to $\mathrm{CTH}$. ${ }^{*} \mathrm{P}<0.05$ for Binet $\mathrm{B}$ when compared with Binet A, following 6 months. CLL, chronic lymphocytic leukemia.
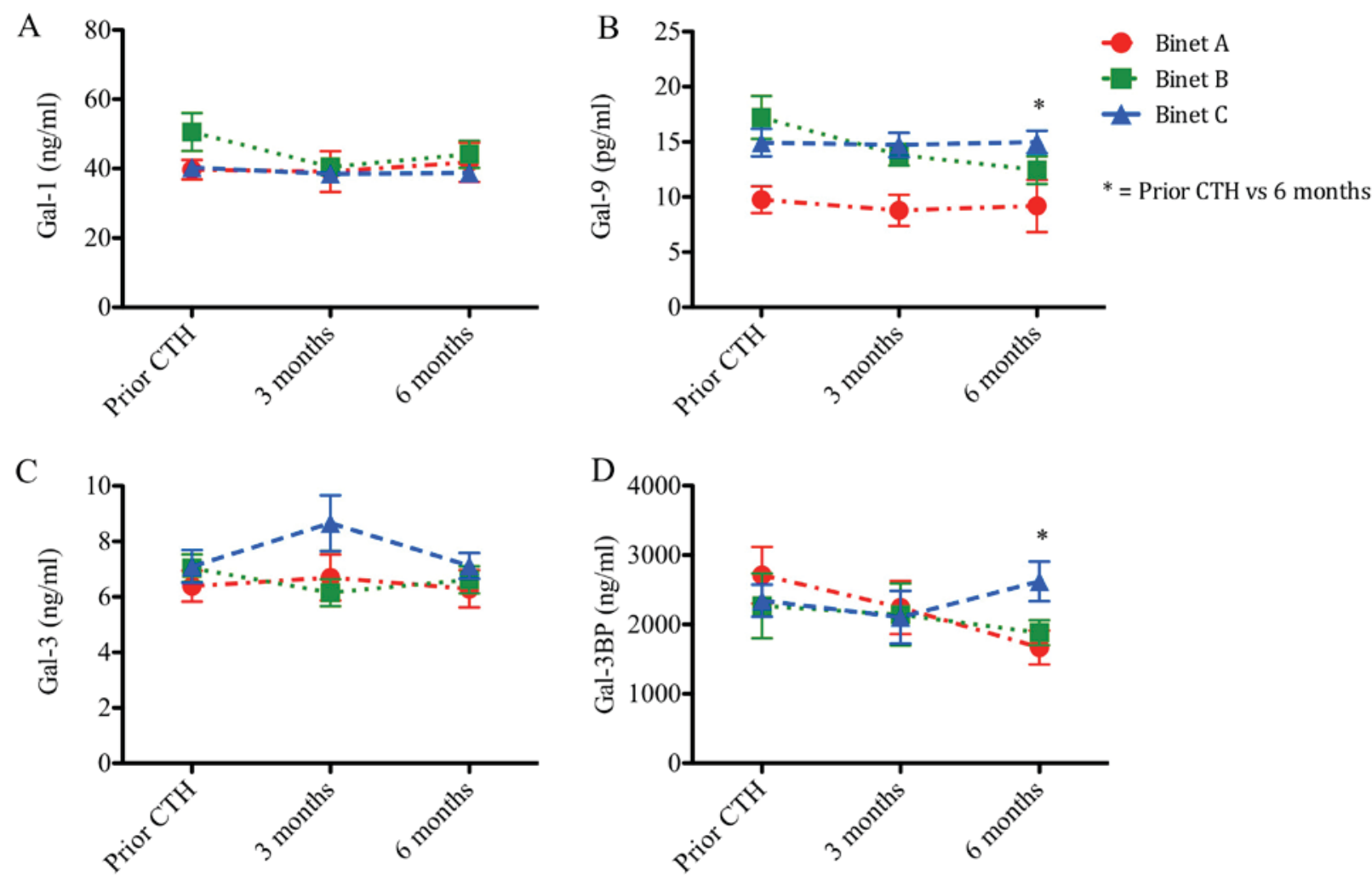

Figure 5. Galectin protein levels in patients with CLL stratified by Binet stage. Concentration of (A) galectin-1, (B) galectin-9, (C) galectin-3 and (D) galectin 3-binding protein in patients with CLL at Binet stage A, B or C and prior to chemotherapy (Prior CT), during chemotherapy (3 months) or following chemotherapy $(6$ months). Binet A $(n=14)$, Binet B $(n=15)$ and Binet $C(n=19)$. Data are presented as the mean \pm standard error of the mean. Data were analyzed using one-way analysis of variance followed by Dunnett's multiple comparison post-hoc test. ${ }^{*} \mathrm{P}<0.05$. CLL, chronic lymphocytic leukemia. 


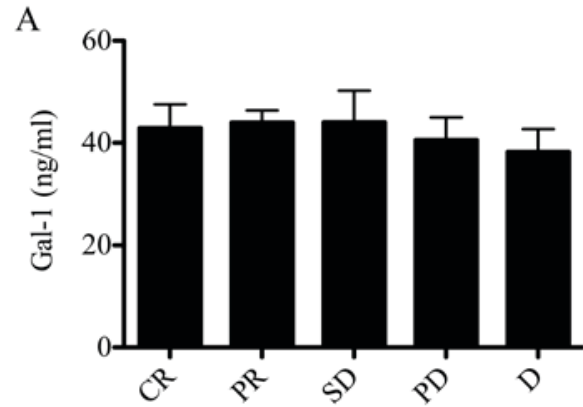

B
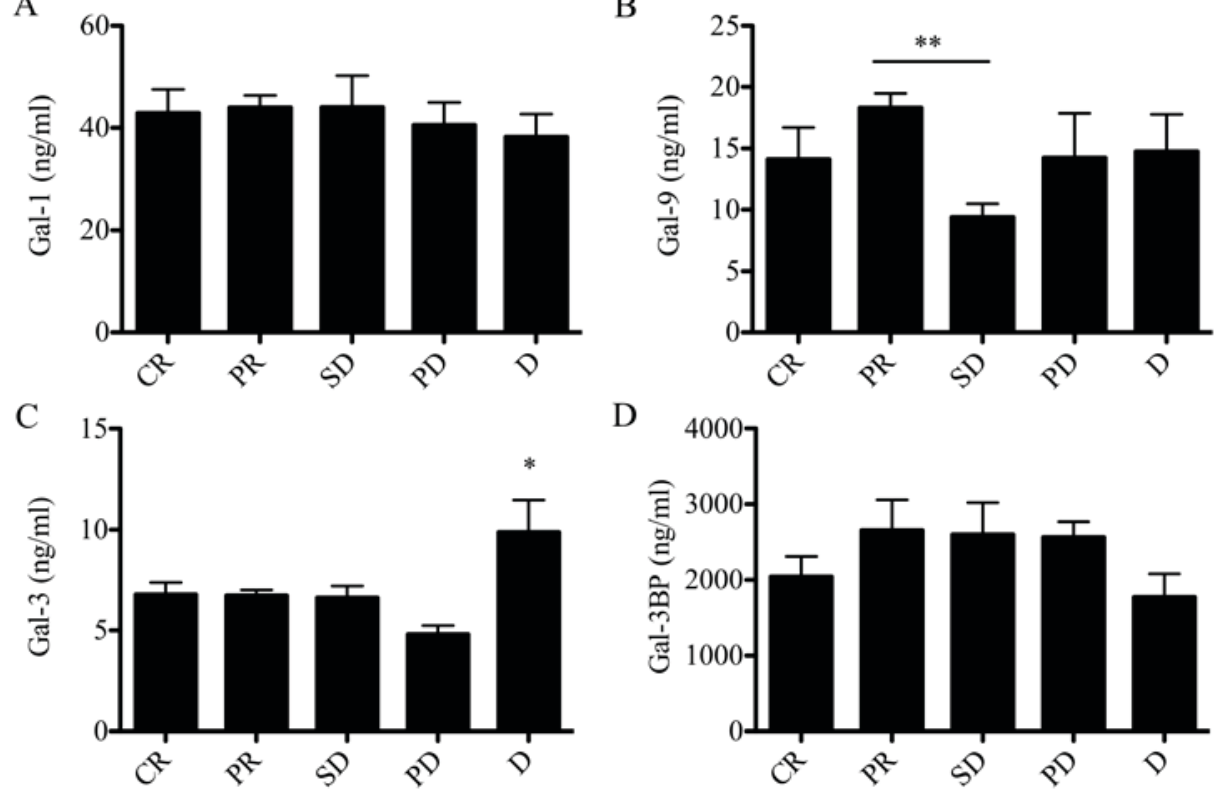

$\mathrm{D}$

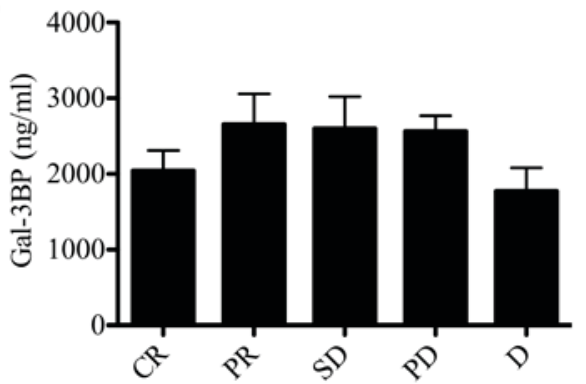

Figure 6. Galectin protein levels in patients with CLL stratified according to IWCLL criteria. Protein concentration of (A) galectin-1, (B) galectin-9, (C) galectin-3 and (D) galectin 3-binding protein in patients with CLL at CR, PR, SD, PD or D. Data are presented as the mean \pm standard error of the mean. Data were analyzed using one-way analysis of variance followed by Dunnett's multiple comparison post-hoc test. "P<0.05 and ${ }^{* *} \mathrm{P}<0.001$. CLL, chronic lymphocytic leukemia; CR, complete remission; PR, partial remission; SD, stable disease; PD, progressive disease; D, death.

A

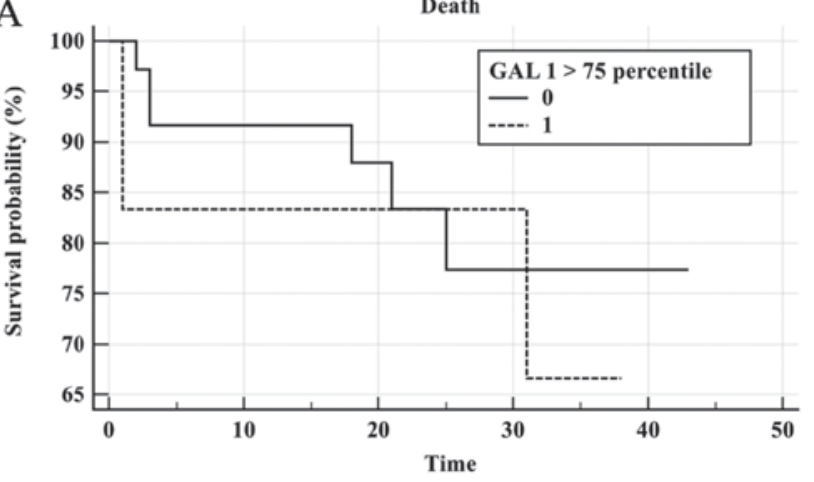

$\mathrm{C}$

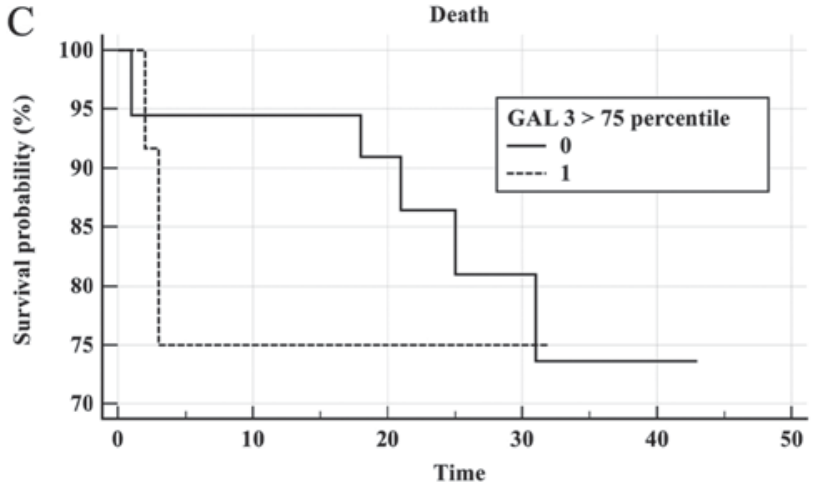

B

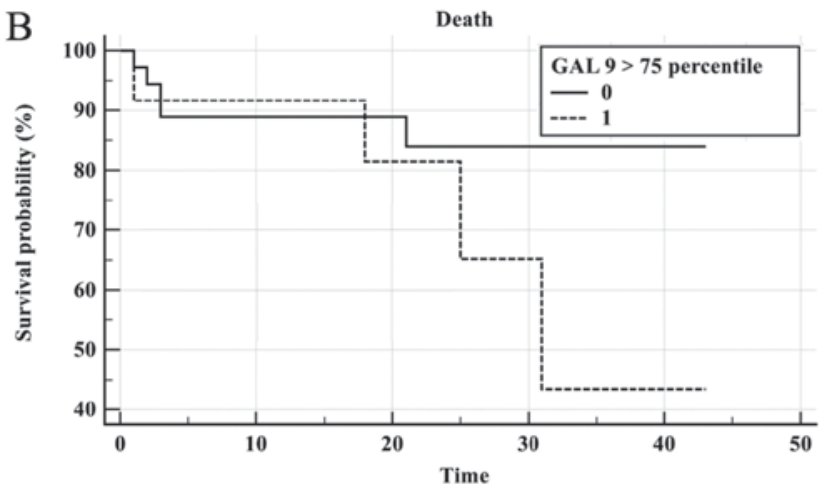

$\mathrm{D}$

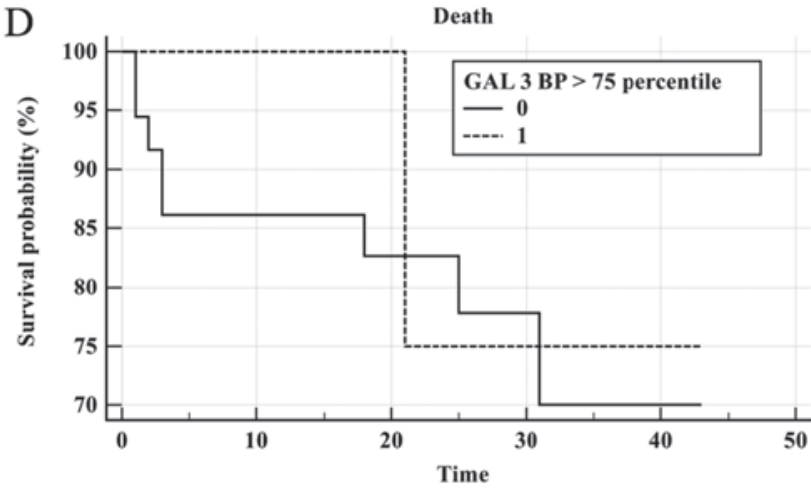

Figure 7. Prognostic impact of galectins for survival of patients with CLL. Kaplan-Meier survival curves of patients with CLL, depicting survival based on (A) galectin-1, (B) galectin-9, (C) galectin-3 and (D) galectin 3-binding protein concentration. Patients were divided into two groups according to whether their galectin levels were above (0) or below (1) the 75th percentile. Tick marks indicate patients who were alive at last follow-up. Follow-up time is presented in months following chemotherapy treatment. CLL, chronic lymphocytic leukemia.

Furthermore, Gal-9 and Tim-3 proteins inhibit the activation of natural killer (NK) cells, blocking the action of NKs on AML cells (48). Subsequently, the Gal-9/Tim-3 signaling pathway is associated with inhibition of the response from Th1 cells in patients with osteosarcoma (49). The Tim-3 receptor, as well as receptors including cytotoxic T-lymphocyte antigen-4 
(CTLA-4), programmed cell death-1 and -2 (PD-1 and PD-2) and lymphocyte activation gene 3 (LAG3), are associated with the transmission of inhibitory signals to lymphocytes (49). These inhibitory signals impair anti-tumor immunity (50). At present, anti-CTLA-4 antibody (ipilimumab in melanoma), anti-PD-1 (nivolumab and pembrolizumab in melanoma and lung cancer) and anti-programmed death ligand 1 (atezolizumab in lung cancer) have been used in cancer immunotherapy (51-55). Restoring the function of T lymphocytes by blocking a signaling pathway associated with Gal-9/Tim-3 may be a potential therapeutic option for patients with cancer, including those with CLL.

In the current study, higher levels of Gal-9 in patients with CLL were correlated with disease progression, negative prognostic factors and response to treatment. However, no significant effects of galectins on OS and PFS were observed, this is potentially due to the small number of patients in the patient cohort. Furthermore, patients in Binet B stage exhibited higher concentrations of Gal-9 compared with patients in Binet $\mathrm{C}$ stage. Patients whose disease was advanced (Binet C) exhibited more severe symptoms compared with those in the intermediate stage of the disease (Binet B), including lymph node involvement, splenomegaly and white blood cell count. An altered lymph node microenvironment retains Gal-9, reducing circulating levels of Gal-9. Furthermore, galectin production by tumor cells during disease progression may be negatively regulated by accumulation of Gal-9 in the extracellular matrix, acting as an autocrine regulatory signal. Finally, elevated Gal-9 levels may also result from clonal expansion and dynamic development of CLL. A large body of evidence suggests that CLL is a clonal disease, consisting of cells of different phenotypes (56). Patients with a lower disease stage may develop a clonal expansion of tumor cells with a different growth rate and needs, compared with clone cells in patients with more advanced disease. Additionally, different Gal-9 isoforms are expressed in tumor clonal cells, which may stimulate the production of other isoforms by such clones (57).

In summary, the potential prognostic factor of Gal-9 in patients with CLL requires further investigation. In the present study, a difference in Gal-9 concentration between the study and control groups was demonstrated, and a correlation was identified between Gal-9 levels and negative prognostic factors, including del11q, del17p, LDH, B2M and response to treatment. An association was observed between Gal-9 levels and progression of CLL or patient mortality. However, these findings are limited by the number of patients investigated in the present study. Therefore, further studies with larger groups of patients should be performed. Future therapeutic strategies for the treatment of CLL may involve the use of galectin inhibitors, including competitive carbohydrates, small non-carbohydrate binding molecules and antibodies.

\section{Acknowledgements}

Not applicable.

\section{Funding}

The present study was supported by internal grant from the Medical University of Silesia (grant no. KNW-1-025/K/7/K).

\section{Availability of data and materials}

The datasets used and/or analyzed during the current study are available from the corresponding author on reasonable request.

\section{Authors' contributions}

TF, PF and KW made substantial contributions to the conception and the design of the present study and were involved in the acquisition analysis and interpretation of data. EC was involved in analysis and interpretation of data, and drafting the manuscript. NA, MW, MK and IG performed the statistical analyses and were involved in data management and critical appraise of the manuscript. TF, JC and JW contributed to the study design and the critical revision and final approval of the present manuscript. All authors read and approved the final version of the manuscript.

\section{Ethics approval and consent to participate}

The study was conducted in adherence with the Declaration of Helsinki Guidelines and was approved by the Bioethics Committee of Silesian Medical University in Katowice (approval no. KNW/0022/KB1/102/13). Upon admission, all patients provided written informed consent for their participation in this project.

\section{Patient consent for publication}

Not applicable.

\section{Competing interests}

The authors declare that they have no competing interests.

\section{References}

1. Shanafelt TD, Byrd JC, Call TG, Zent CS and Kay NE: Narrative review: Initial management of newly diagnosed, early-stage chronic lymphocytic leukemia. Ann Intern Med 145: 435-447, 2006.

2. Zenz T, Mertens D, Küppers R, Döhner H and Stilgenbauer S: From pathogenesis to treatment of chronic lymphocytic leukaemia. Nat Rev Cancer 10: 37-50, 2010.

3. Zhang S and Kipps T: The pathogenesis of chronic lymphocytic leukemia. Annu Rev Pathol 9: 103-118, 2014.

4. Döhner H, Stilgenbauer S, Benner A, Leupolt E, Kröber A, Bullinger L, Döhner K, Bentz M and Lichter P: Genomic aberrations and survival in chronic lymphocytic leukemia. N Engl J Med 343: 1910-1916, 2000.

5. Kipps TJ, Stevenson FK, Wu CJ, Croce CM, Packham G, Wierda WG, O'Brien S, Gribben J and Rai K: Chronic lymphocytic leukaemia. Nat Rev Dis Primers 3, 16096, 2017.

6. Balatti V, Pekarky Y and Croce CM: Role of microRNA in chronic lymphocytic leukemia onset and progression. J Hematol Oncol 8: 12, 2015.

7. Fabbri M, Bottoni A, Shimizu M, Spizzo R, Nicoloso MS, Rossi S, Barbarotto E, Cimmino A, Adair B, Wojcik SE, et al: Association of a microRNA/TP53 feedback circuitry with pathogenesis and outcome of B-cell chronic lymphocytic leukemia. JAMA 305: 59-67, 2011

8. Martín-Subero JI, López-Otín C and Campo E: Genetic and epigenetic basis of chronic lymphocytic leukemia. Curr Opin Hematol 20: 362-368, 2013.

9. Kröber A, Seiler T, Benner A, Bullinger L, Brückle E, Lichter P, Döhner $\mathrm{H}$ and Stilgenbauer S: V(H) mutation status, CD38 expression level, genomic aberrations, and survival in chronic lymphocytic leukemia. Blood 100: 1410-1416, 2002. 
10. Ghia P, Stamatopoulos K, Belessi C, Moreno C, Stilgenbauer S, Stevenson F, Davi F and Rosenquist R; European Research Initiative on CLL: ERIC recommendations on IGHV gene mutational status analysis in chronic lymphocytic leukemia. Leukemia 21: 1-3, 2007.

11. Amaya-Chanaga CI and Rassenti LZ: Biomarkers in chronic lymphocytic leukemia: Clinical applications and prognostic markers. Best Pract Res Clin Haematol 29: 79-89, 2016.

12. D'Arena G, Musto P, Cascavilla N, Dell'Olio M, Di Renzo N, Perla G, Savino L and Carotenuto M: CD38 expression correlates with adverse biological features and predicts poor clinical outcome in B-cell chronic lymphocytic leukemia. Leuk Lymphoma 42: 109-114, 2001.

13. Hayat A, O'Brien D, O'Rourke P, McGuckin S, Fitzgerald T, Conneally E, Browne PV, McCann SR, Lawler MP and Vandenberghe E: CD38 expression level and pattern of expression remains a reliable and robust marker of progressive disease in chronic lymphocytic leukemia. Leuk Lymphoma 47: 2371-2379, 2006.

14. Oscier DG, Rose-Zerilli M, Winkelmann N, Gonzalez de Castro D, Gomez B, Forster J, Parker H, Parker A, Gardiner A, Collins A, et al: The clinical significance of NOTCH1 and SF3B1 mutations in the UK LRF CLL4 trial. Blood 121: 468-475, 2013.

15. Dürig J, Naschar M, Schmücker U, Renzing-Köhler K, Hölter T, Hüttmann A and Dührsen U: CD38 expression is an important prognostic marker in chronic lymphocytic leukaemia. Leukemia 16: 30-35, 2002.

16. Del Poeta G, Maurillo L, Venditti A, Buccisano F, Epiceno AM, Capelli G, Tamburini A, Suppo G, Battaglia A, Del Principe MI, et al: Clinical significance of CD38 expression in chronic lymphocytic leukemia. Blood 98: 2633-2639, 2001.

17. Rassenti LZ, Jain S, Keating ML, Wierda WG, Grever MR, Byrd JC, Kay NE, Brown JR, Gribben JG, Neuberg DS, et al: Relative value of ZAP-70, CD38, and immunoglobulin mutation status in predicting aggressive disease in chronic lymphocytic leukemia. Blood 112: 1923-1930, 2008.

18. Ghia P, Guida G, Stella S, Gottardi D, Geuna M, Strola G, Scielzo C and Caligaris-Cappio F: The pattern of CD38 expression defines a distinct subset of chronic lymphocytic leukemia (CLL) patients at risk of disease progression. Blood 101: 1262-1269, 2003.

19. Rai KR, Sawitsky A, Cronkite EP, Chanana AD, Levy RN and Pasternack BS: Clinical staging of chronic lymphocytic leukemia. Blood 46: 219-234, 1975.

20. Binet JL, Auquier A, Dighiero G, Chastang C, Piguet H, Goasguen J, Vaugier G, Potron G, Colona P, Oberling F, et al: A new prognostic classification of chronic lymphocytic leukemia derived from a multivariate survival analysis. Cancer 48: 198-206, 1981

21. Wierda WG, O'Brien S, Wang X, Faderl S, Ferrajoli A, Do KA, Cortes J, Thomas D, Garcia-Manero G, Koller C, et al: Prognostic nomogram and index for overall survival in previously untreated patients with chronic lymphocytic leukemia. Blood 109 4679-4685, 2007.

22. Pinho SS and Reis CA: Glycosylation in cancer: Mechanisms and clinical implications. Nat Rev Cancer 15: 540-555, 2015.

23. Varki A, Kannagi R and Toole BP: Glycosylation changes in cancer. In Essentials of Glycobiology. 2nd edition: Varki A, Cummings RD, Esko JD, Freeze HH, Stanley P, Bertozzi CR, Hart GW and Etzler ME (eds): Cold spring harbor laboratory press: NY, 2017.

24. Oliveira-Ferrer L, Legler K and Milde-Langosch K: Role of protein glycosylation in cancer metastasis. Semin Cancer Biol 44: 141-152, 2017.

25. Ebrahim AH, Alalawi Z, Mirandola L, Rakhshanda R, Dahlbeck S, Nguyen D, Jenkins M, Grizzi F, Cobos E, Figueroa JA and Chiriva-Internati M: Galectins in cancer : Carcinogenesis, diagnosis and therapy. Ann Transl Med 2: 88, 2014.

26. Giordano M, Croci DO and Rabinovich GA: Galectins in hematological malignancies. Curr Opin Hematol 20: 327-335, 2013.

27. Pena C, Mirandola L, Figueroa JA, Hosiriluck N, Suvorava N, Trotter K, Reidy A, Rakhshanda R, Payne D, Jenkins M, et al: Galectins as therapeutic targets for hematological malignancies: A hopeful sweetness. Ann Transl Med 2: 87, 2014.

28. Cousin JM and Cloninger MJ: The role of galectin-1 in cancer progression, and synthetic multivalent systems for the study of Galectin-1. Int J Mol Sci 17: pii: E1566, 2016.

29. Asgarian-Omran H, Forghani P, Hojjat-Farsangi M, Roohi A, Sharifian RA, Razavi SM, Jeddi-Tehrani M, Rabbani H and Shokri F: Expression profile of galectin-1 and galectin-3 molecules in different subtypes of chronic lymphocytic leukemia. Cancer Invest 28: 717-725, 2010.
30. Chen C, Duckworth CA, Zhao Q, Pritchard DM, Rhodes JM and Yu LG: Increased circulation of galectin-3 in cancer induces secretion of metastasis-promoting cytokines from blood vascular endothelium. Clin Cancer Res 19: 1693-1704, 2013.

31. Colomb F, Wang W, Simpson D, Zafar M, Beynon R, Rhodes JM and Yu LG: Galectin-3 interacts with the cell-surface glycoprotein CD146 (MCAM, MUC18) and induces secretion of metastasis-promoting cytokines from vascular endothelial cells. J Biol Chem 292: 8381-8389, 2017.

32. Taghiloo S, Allahmoradi E, Ebadi R, Tehrani M,Hosseini-Khah Z, Janbabaei G, Shekarriz R and Asgarian-Omran H: Upregulation of Galectin-9 and PD-L1 immune checkpoints molecules in patients with chronic lymphocytic leukemia. Asian Pac J Cancer Prev 18: 2269-2274, 2017.

33. Junking M and Wongkham C: Decreased expression of galectin-3 is associated with metastatic potential of liver fluke-associated cholangiocarcinoma. Eur J Cancer, 44: 619, 2008-626.

34. Lee JW, Song SY, Choi JJ, Choi CH, Kim TJ, Kim J, Lee JH, Kim BG and Bae DS: Decreased galectin-3 expression during the progression of cervical neoplasia. J Cancer Res Clin Oncol 132: 241-247, 2006.

35. Matsuda Y, Yamagiwa Y, Fukushima K, Ueno Y and Shimosegawa T: Expression of galectin-3 involved in prognosis of patients with hepatocellular carcinoma. Hepatol Res 38: 1098-1111, 2008

36. Prieto VG, Mourad-Zeidan AA, Melnikova V, Johnson MM, Lopez A, Diwan AH, Lazar AJ, Shen SS, Zhang PS, Reed JA, et al: Galectin-3 expression is associated with tumor progression and pattern of sun exposure in melanoma. Clin Cancer Res 12: 6709-6715, 2006.

37. Nakahara S, Oka N and Raz A: On the role of galectin-3 in cancer apoptosis. Apoptosis 10: 267-275, 2005.

38. Koyama S, Akbay E, Li YY, Herter-Sprie GS, Buczkowski KA, Richards WG, Gandhi L, Redig AJ, Rodig SJ, Asahina H, et al: Adaptive resistance to therapeutic PD-1 blockade is associated with upregulation of alternative immune checkpoints. Nat Commun 7: 10501, 2016.

39. Sakuishi K, Apetoh L, Sullivan JM, Blazar BR, Kuchroo VK and Anderson AC: Targeting Tim-3 and PD-1 pathways to reverse T cell exhaustion and restore anti-tumor immunity. J Exp Med 207: 2187-2194, 2010.

40. Zhou Q, Munger M, Veenstra RG, Weigel BJ, Hirashima M, Munn DH, Murphy WJ, Azuma M, Anderson AC, Kuchroo VK and NBlazar BR: Coexpression of Tim-3 and PD-1 identifies a CD8+ T-cell exhaustion phenotype in mice with disseminated acute myelogenous leukemia. Blood, 117: 4501-4510, 2011.

41. Dalotto-Moreno T, Croci D, Cerliani JP, Martinez-Allo VC, Dergan-Dylon S, Méndez-Huergo SP, Stupirski JC, Mazal D, Osinaga E, Toscano MA, et al: Targeting galectin-1 overcomes breast cancer-associated immunosuppression and prevents metastatic disease. Cancer Res 73: 1107-1117, 2013.

42. Cedeno-Laurent F, Watanabe R, Teague JE, Kupper TS, Clark RA and Dimitroff CJ: Galectin-1 inhibits the viability, proliferation, and Th1 cytokine production of nonmalignant $\mathrm{T}$ cells in patients with leukemic cutaneous T-cell lymphoma. Blood 119: 3534-3538, 2012.

43. Hallek M, Cheson BD, Catovsky D, Caligaris-cappio F, Dighiero G, Döhner H, Hillmen P, Keating MJ, Montserrat E, Rai KR, et al: Guidelines for the diagnosis and treatment of chronic lymphocytic leukemia: A report from the international workshop on chronic lymphocytic leukemia updating the national cancer institute-Working Group 1996 guidelines. Blood 111: 5446-5456, 2008.

44. Hallek M: Chronic lymphocytic leukemia: 2015 update on diagnosis, risk stratification, and treatment. Am J Hematol 90: 446-460, 2015

45. Eichhorst B, Robak T, Montserrat E, Ghia P, Hillmen P, Hallek M and Buske C; ESMO Guidelines Committee: Chronic lymphocytic leukaemia: ESMO clinical practice guidelines for diagnosis, treatment and follow-up. Ann Oncol 26 (Suppl 5): v78-v84, 2015.

46. Croci DO, Morande PE, Dergan-Dylon S, Borge M, Toscano MA, Stupirski JC, Bezares RF, Avalos JS, Narbaitz M, Gamberale R, et al: Nurse-like cells control the activity of chronic lymphocytic leukemia B cells via galectin-1. Leukemia 27: 1413-1416, 2013.

47. Kikushige Y, Miyamoto T, Yuda J, Jabbarzadeh-Tabrizi S, Shima T, Takayanagi S, Niiro H, Yurino A, Miyawaki K, Takenaka K, et al: A TIM-3/Gal-9 autocrine stimulatory loop drives self-renewal of human myeloid leukemia stem cells and leukemic progression. Cell Stem Cell 17: 341-352, 2015. 
48. Goncalves Silva I, Yasinska IM, Sakhnevych SS, Fiedler W, Wellbrock J, Bardelli M, Varani L, Hussain R, Siligardi G, Ceccone G, et al: The Tim-3-galectin-9 secretory pathway is involved in the immune escape of human acute myeloid leukemia cells. EBioMedicine 22: 44-57, 2017.

49. Li X, Chen Y, Liu X,Zhang J, He X, Teng G and Yu D: Tim3/Gal9 interactions between $\mathrm{T}$ cells and monocytes result in an immunosuppressive feedback loop that inhibits Th1 responses in osteosarcoma patients. Int Immunopharmacol 44: 153-159, 2017.

50. Ozkazanc D, Yoyen-Ermis D, Tavukcuoglu E, Buyukasik Y and Esendagli G: Functional exhaustion of $\mathrm{CD}^{+} \mathrm{T}$ cells induced by co-stimulatory signals from myeloid leukaemia cells. Immunology 149: 460-471, 2016.

51. Rittmeyer A, Barlesi F, Waterkamp D, Park K, Ciardiello F, von Pawel J, Gadgeel SM, Hida T, Kowalski DM, Dols MC, et al: Atezolizumab versus docetaxel in patients with previously treated non-small-cell lung cancer (OAK): A phase 3, open-label, multicentre randomised controlled trial. Lancet 389: 255-265, 2017.

52. Fehrenbacher L, Spira A, Ballinger M, Kowanetz M, Vansteenkiste J, Mazieres J, Park K, Smith D, Artal-Cortes A, Lewanski C, et al: Atezolizumab versus docetaxel for patients with previously treated non-small-cell lung cancer (POPLAR) A multicentre, open-label, phase 2 randomised controlled trial. Lancet 387: 1837-1846, 2016.

53. Wolchok JD, Chiarion-Sileni V, Gonzalez R, Rutkowski P, Grob JJ, Cowey CL, Lao CD, Wagstaff J, Schadendorf D, Ferrucci PF, et al: Overall survival with combined nivolumab and ipilimumab in advanced melanoma. N Engl J Med 377: 1345-1356, 2017.
54. Herbst RS, Baas P, Kim DW, Felip E, Pérez-Gracia JL, Han JY, Molina J, Kim JH, Arvis CD, Ahn MJ, et al: Pembrolizumab versus docetaxel for previously treated,PD-L1-positive, advanced non-small-cell lung cancer (KEYNOTE-010): A randomised controlled trial. Lancet 387: 1540-1550, 2016.

55. Reck M, Rodríguez-Abreu D, Robinson AG, Hui R, Csőszi T, Fülöp A, Gottfried M, Peled N, Tafreshi A, Cuffe S, et al: Pembrolizumab versus Chemotherapy for PD-L1-positive non-small-cell lung cancer. N Engl J Med 375: 1823-1833, 2016.

56. Hurtado AM, Chen-Liang TH, Przychodzen B, Hamedi C, Muñoz-Ballester J, Dienes B, García-Malo MD, Antón AI, de Arriba F, Teruel-Montoya R, et al: Prognostic signature and clonality pattern of recurrently mutated genes in inactive chronic lymphocytic leukemia. Blood Cancer J 5: e342, 2015.

57. Sato M, Nishi N, Shoji H, Seki M, Hashidate T, Hirabayashi J, Kasai Ki K, Hata Y, Suzuki S, Hirashima M and Nakamura T: Functional analysis of the carbohydrate recognition domains and a linker peptide of galectin-9 as to eosinophil chemoattractant activity. Glycobiology 12: 191-197, 2002.

(c) (5) This work is licensed under a Creative Commons EY Attribution 4.0 International (CC BY-NC 4.0) License 